\title{
Microemulsion Based Formulation as Drug Delivery System for Gliclazide
}

\author{
Harsha Kamath ${ }^{1}$ and A Sivakumar ${ }^{2 *}$ \\ ${ }^{1}$ Department of Pharmaceutical Chemistry, Karnataka College of Pharmacy, \#33/2, Thirumanahalli, Hegdenagar Main Road, Bengaluru, \\ Karnataka, INDIA. \\ ${ }^{2}$ Department of Chemistry, School of Advanced Sciences, Vellore Institute of Technology, Vellore, Tamilnadu, INDIA.
}

\begin{abstract}
Purpose: The present study is intended to develop and evaluate oil in water (O/W) microemulsion based formulation for gliclazide as oral drug delivery system for the treatment of diabetes mellitus. Gliclazide, having sulphonyl urea moiety (Class II of BCS system) is a hydrophobic drug. Methods: Oil in water microemulsion was formulated using water titration method. Viscosity, $\mathrm{pH}$, conductivity, particle size and thermodynamic stability studies were carried out for optimization followed by In vitro drug release and in vivo pharmacokinetic study. Results: The formulated O/W microemulsion had olive oil, tween 80 and propylene glycol as ingredients with an average particle size $14.3 \mathrm{~nm}$. The developed formulation showed a drug release of $82.4 \%$ while the pure drug in powdered form showed a release of $32.19 \%$ as observed through in vitro drug release studies. The data obtained by these studies was fitted to zero order, first order Higuchi and Korsmeyer Pappas models. The in vivo pharmacokinetic parameters of the optimized microemulsion was significantly $(P<0.05)$ different when compared to the conventional tablet formulation. The peak serum concentration $\left(C_{\max }\right)$ for the microemulsion $(2.998 \pm 0.419$ $\mu \mathrm{g} / \mathrm{mL})$ was higher than that for the conventional tablet $(2.118 \pm 0.169 \mu \mathrm{g} / \mathrm{mL})$, and the time required to reach the peak serum concentration $\left(T_{\max }\right)$ was significantly shorter for the optimized microemulsion $(2.5 \pm 0.548 \mathrm{~h})$ compared to the tablet formulation $(5.333 \pm 1.033 \mathrm{~h})$. Conclusion: Gliclazide $\mathrm{O} / \mathrm{W}$ microemulsion was found to be stable and showed superior in vitro and in vivo release. The study promises improved clinical efficacy for gliclazide as $\mathrm{O} / \mathrm{W}$ microemulsion in the management of type 2 diabetes.
\end{abstract}

Key words: Microemulsion, Gliclazide, Immediate release, Pharmacokinetics, Thermodynamic stability, in vitro diffusion.

\section{INTRODUCTION}

Diabetes Mellitus commonly known as hyperglycemia is a collection of disorders primarily due to defective insulin release (Type I Diabetes Mellitus) or insulin sensitivity (Type II Diabetes Mellitus). Type I diabetes or Insulin Dependent Diabetes Mellitus (IDDM) is predominantly known as genetic disorder seen in children while Type II diabetes or Non-Insulin Dependent Diabetes Mellitus (NIDDM) is known as lifestyle disorder seen in adults. IDDM is treated with insulin and its analogues while NIDDM treatment involves oral therapy with hypoglycemic agents.
Gliclazide, an oral hypoglycemic agent is chemically a sulfonylurea, specifically [1-[(4-methyl benzene)sulfonyl $]-3-$ \{octahydrocyclopenta[c]pyrrol-2-yl\}] urea. This drug is an insulin secretogogue with the mechanism that stimulates $\beta$ cells of pancreas which release insulin thus controlling the blood sugar levels. Gliclazide belongs to class II drugs in Biopharmaceutics Classification System (BCS) ${ }^{1,2}$ which comprises of poorly soluble and highly permeable drugs. The low water solubility of gliclazide results in a low dissolution rate with inadequate and variable bioavailability ${ }^{3}$.
Submission Date: 22-03-2017; Revision Date: 05-05-2017; Accepted Date: 27-09-2017

DOI: 10.5530/ijper.51.4s.85 Correspondence: A. Sivakumar, Department of Chemistry, School of Advanced Sciences, Vellore Institute of Technology, Vellore, 632014, Tamilnadu, India.

Phone no: 08124154599; E-mail: adi@vit.ac.in

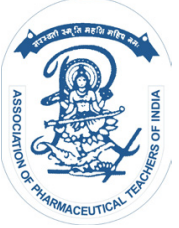

www.ijper.org 
Poorly soluble drugs often offer challenge not only for the formulation design and development but also for the screening studies. Among several strategies adapted to improve bioavailability, the major concern has always been on enhancing drug's water solubility ${ }^{1,4,5}$. Solubility of the active pharmaceutical ingredient (API) in the gastric medium is of prime significance as its fair absorption through the intestine and its bioavailability depends on this property. Beside solubility the API must also possess decent permeability through brush border epithelial cells of small intestine which decides the bioavailability factor. Since improving aqueous solubility is an important criterion in formulation development, several techniques such as $\mathrm{pH}$ adjustment, hydrotropy, micellar solubilization, micronization (reducing particle size), chemical modification (salts, complexes, prodrugs), solid dispersion, complexation, cosolvency were explored $^{6,7}$. Enhancing permeability could be achieved by using certain surface active agents in the formulation design which would not only improve aqueous solubility but also distupt the inside layer of epithelial cells of the intestine. Since gliclazide is poorly soluble in aqueous solvents, micro-emulsification technique is utilized to reduce the particle size and improve the solubility of this drug.

Microemulsions are thermodynamically stable, isotropic, transparent or translucent systems mostly covering size range of $50-200 \mathrm{~nm} .{ }^{8,9,10}$ They have attracted great attention in oral drug delivery systems for new drug candidates which are poorly soluble in water. These drugs face challenges because they are poorly bioavailable, possess subject variability and pose challenge for dose proportionality. Microemulsion system largely consists of four components: lipophilic phase, hydrophilic phase, surfactant and co-surfactant. The nano sized droplets have large surface area that influence the passage of the drug in the biological system.

The objective of the current study is formulation and evaluation of oil in water immediate release microemulsion system for gliclazide and study the in vitro release kinetics and in vivo pharmacokinetics.

\section{MATERIALS AND METHODS}

\section{Materials}

Gliclazide was a gift sample from Bal Pharma (Bengaluru, Karnataka, India). Polyethylene glycol 400 (PEG 400), Polysorbate 80 (Tween 80), Isopropyl Myristate (IPM), propylene glycol, methanol were procured from Merck (Schuchardt, Germany). Almond oil, soyabean oil, rice bran oil, olive oil, coconut oil, arachis oil and castor oil were obtained from standard sources. Milli-Q-water (Millipore, USA) was used throughout the process.

\section{Preformulation studies}

\section{Solubility study}

For preparation of microemulsion, different components were selected through solubility study using equilibration method $^{11}$. A known quantity of the drug was dissolved in each of the oils, surfactants and cosurfactants by vortexing in stoppered vials, followed by shaking at $100 \mathrm{rpm}$ for $72 \mathrm{hr}$ on an orbital shaker at $25 \pm 1^{\circ} \mathrm{C}$. These mixtures were then centrifuged at $3000 \mathrm{rpm}$ for $15 \mathrm{~min}$ and the supernatant was filtered through $0.45 \mu \mathrm{m}$ membrane filter. The dissolved drug was diluted within the linearity range and was measured spectrophotometrically using double beam uv-spectrophotometer (Shimadzu UV-1700) at $228 \mathrm{~nm}$.

\section{Drug-excipient compatibility studies}

Fourier Transform Infra Red analysis (FTIR) was used to study drug-excipient interaction by scanning the samples in the range of $400-4000 \mathrm{~cm}^{-1}$. The pure drug was mixed with surfactant, co-surfactant and oil and this mixture was analyzed. Spectral comparison was done with FTIR of pure drug to eliminate the possibility of important functional groups of the drug interacting with the excipients.

\section{Pseudoternary phase diagrams}

Simple water titration method by varying the ratio of oil, surfactant and co-surfactant is used to prepare a series of mixtures. A mixture of surfactants and co-surfactants were prepared initially $(1: 1,1: 2,1: 4,1: 6,1: 8,1: 10,1: 12)$ and fixed volume of oil was introduced into these mixtures by gentle shaking and vortexing. The resulted mixture was titrated with water slowly with constant stirring on magnetic stirrer to allow equilibration. The end point of the titration could be identified by the turbid solution becoming transparent. Appearance of milky white and turbid mixtures indicated unstable emulsions that sooner or later phase separated and thus termed bi-phasic. The clear, transparent or translucent, low viscous mixtures indicated that they are monophasic. They were kept under observation at room temperature for a day.

The different ratios of oil, surfactant, co-surfactant and water from the titrations that resulted in monophasic mixtures were plotted on three diagonals of the triangle to construct pseudoternary phase diagram (Chemix software CHEMIX School 3_60, Evaluation Copy). The shaded area represented monophasic emulsions and considered as the area of existence of stable microemulsions. All titrations were repeated twice to get reproducible results.

Drug loaded microemulsions prepared by solubilizing drug in the oil and further following the same procedure 
as described earlier for microemulsification, were also used for plotting pseudoternary Phase diagrams. The influence of the drug on microemulsion area was observed.

\section{Evaluation of Microemulsion System: Thermodynamic stability studies}

The thermodynamic stability of gliclazide microemulsion was evaluated using following stress tests in series. Physical stability of the formulations were checked by centrifugation at $3000 \mathrm{rpm}$ for $30 \mathrm{~min}$. Those formulations which didn't cream, crack or separate into two layers were subjected to the next test.

The stability of the formulations at extreme temperatures was tested by storing them at $45^{\circ} \mathrm{C}$ and $4^{\circ} \mathrm{C}$ each for a period of $48 \mathrm{hr}$. This heating and cooling cycle was repeated six times. The formulations which were stable at these temperatures were progressed on to the next test.

The next stress test is freeze-thaw cycle that involved storing the formulations between $-21^{\circ} \mathrm{C}$ and $+25^{\circ} \mathrm{C}$ each for a minimum period of $48 \mathrm{hr}$.

The formulations that passed these stress studies were considered thermodynamically stable and selected for further optimization.

\section{Physicochemical characterization}

\section{Conductivity measurement}

Electrical conductivity $(\sigma)$ of the drug loaded microemulsions was studied using a conductivity meter (Elico CM 180). This measurement was done to study the effect of the amount of water in the microemulsion and to ascertain the type of the system; oil-continuous, bi-continuous or water continuous.

pH

The $\mathrm{pH}$ values of drug loaded microemulsions were measured using a calibrated $\mathrm{pH}$ meter (Mettler Toledo, pHcompact 220$)$ at $25 \pm 1^{\circ} \mathrm{C}$. The measurements were done in triplicate.

Viscosity

Viscosity measurement of the microemulsions was done in triplicates using Brookfield viscometer (DV-III + , Programmable rheometer).

Droplet size, polydispersity index and zeta potential measurement

The droplet size, polydispersity index and zeta potential of the optimized formulation was measured by dynamic light scattering (DLS) using Malvern Zetasizer (S-90 Nano series).

\section{In-vitro diffusion study}

The drug permeability study was executed by using a Franz diffusion cell fitted with a 0.45 micron cellulose membrane pre-hydrated in distilled water at $25^{\circ} \mathrm{C}$ for $24 \mathrm{hr}^{12}$ The receptor compartment was filled with 6.8 $\mathrm{pH}$ phosphate buffer and the donor compartment was charged with $10 \mathrm{mg}$ of pure drug or $5 \mathrm{~mL}$ of the microemulsions. The diffusion medium was continuously stirred with a magnetic stirrer at $100 \mathrm{rpm}$ throughout the experiment (Remi 2MLH). $2 \mathrm{~mL}$ of the sample was withdrawn from the receptor compartment at $1 \mathrm{hr}$ time interval till 8 hours and immediately replaced with an equal volume of fresh buffer. The samples withdrawn were diluted with diffusion medium and the absorbance was measured spectrophotometrically at $228 \mathrm{~nm}$. The percentage cumulative drug release was determined for the pure drug as well as the formulated microemulsion.

\section{Accelerated stability study}

The accelerated stability study was conducted as per $\mathrm{ICH}$ guidelines ${ }^{13}$ at $25^{\circ} \mathrm{C} \pm 2^{\circ} \mathrm{C} / 60 \% \pm 5 \%$ relative humidity $(\mathrm{RH})$ and $40^{\circ} \mathrm{C} \pm 2^{\circ} \mathrm{C} / 75 \% \pm 5 \% \mathrm{RH}$ in the stability chambers (Thermo labs). Approximately $5 \mathrm{~mL}$ of the formulation is stored in tightly screw capped bottle. This 6 month study involved collection of samples at the interval of one, two, three and six months. The formulation was evaluated for various parameters such as physical appearance, phase separation at accelerated gravitational force, active ingredient content and globule size determination. Globule size was determined microscopically (Jenoptics optical systems with software ProgResRCapturePro2.7.7) throughout the study period to ascertain uniformity.

\section{Determination of drug content}

The drug was extracted from the drug loaded microemulsion using methanol and was appropriately diluted and the drug content was measured by recording the $\mathrm{UV} / \mathrm{Vis}$ spectrum by absorption peak at $228 \mathrm{~nm}$ as well as by HPLC. The HPLC method was developed in house and the Chromatographic conditions were optimized for assay were; Stationary phase as $\mathrm{C} 185 \mu \mathrm{m} 250 \times 4.6 \mathrm{~mm}$ (WatersXBridge), flow rate at $1 \mathrm{~mL} / \mathrm{min}$, mobile phase as Methanol: $0.1 \%$ Trifluroaceticacid buffer (80:20), column temperature of $25^{\circ} \mathrm{C}$, injection volume of $20 \mu \mathrm{L}$, detection wavelength at $227 \mathrm{~nm}$ and run time of $8 \mathrm{~min}$.

\section{In-vivo pharmacokinetic study}

The study conducted was approved by Institutional animal ethical committee of Karnataka College of Pharmacy, Bangalore (No.1564/PO/a/11/CPCSEA). 


\section{Animals}

Albino rabbits of both sex and of 3 months of age were used as study animals. They weighed between 1.35 to $1.75 \mathrm{Kg}$. Two groups comprising six rabbits in each group were formed; one group was administered with conventional tablet and second group with microemulsion. The animal laboratory maintained the temperature of $25 \pm 2^{\circ} \mathrm{C}$ and $50 \pm 15 \%$ relative humidity. The rabbits were given standard pellet diet and had free access to water. They were fasted for $18 \mathrm{~h}$ prior to the experiment. Food and water were withdrawn during the experiment too.

\section{Preparation of animal dose}

Gliclazide is an orally administered drug as anti-diabetic therapy. Human oral therapeutic dose of the drug was extrapolated to rabbit based on body weight. Gliclazide conventional tablets were crushed into powder and dose equivalent to $80 \mathrm{mg}$ of human dose was suspended in $0.5 \%$ sodium carboxy methyl cellulose.

Oral gavage was used to administer both the formulations to the respective groups.

\section{Sample preparation}

The blood samples (about $400-500 \mu \mathrm{L}$ ) collected from marginal ear vein of the rabbits with the help of heparinized needle (24 size) at the fixed time intervals at $0.5,1,2,3,4,6,8$ and $12 \mathrm{hr}$ after oral dosing into the EDTA coated tubes. These tubes were kept on rotating rollers and mixed for $10 \mathrm{~min}$. Then they were centrifuged at $5000 \mathrm{rpm}$ for $5 \mathrm{~min}$. The supernatant clear plasma is separated and stored at $-20^{\circ} \mathrm{C}$ until analysis. Plasma samples were analyzed by HPLC for finding out various pharmacokinetic parameters ${ }^{14}$.

\section{Determination of gliclazide in rabbit plasma by Reverse Phase HPLC}

The plasma samples were analyzed for the determination of the concentration of gliclazide by a standardized reverse phase HPLC method with slight modification. The Agilent 1120 Compact LC-HPLC system with gradient pump (400barr), rheodyne injector, UV variable detector, standard cell and Agilent syringe $(50 \mu \mathrm{L})$ was used. The separations were achieved on Water's XBridge column $(5 \mu \mathrm{m} 4.6 \times 250 \mathrm{~mm})$ with UV detection at $228 \mathrm{~nm}$. Analytical weighing balance (Shimadzu AUX220) was used for weighing, sonicator (EQUITRON230VAC, $50 \mathrm{~Hz}$ ), vacuum pump (SUPERFIT110336), filtration kit (TARSONS) with PALL membrane for solvents and sample filtration were used throughout the experiment. The EZChrome Elite software performed the acquisition, evaluation and storage of the obtained chromatographic data. Acetonitrile: water: trifluoroace- ticacid: triethylamine (55:45:0.1:0.1 v/v) was the mobile phase run with isocratic flow rate of $1 \mathrm{~mL} / \mathrm{min}$., $50 \mu \mathrm{L}$ sample was injected and the peaks were monitored at $\lambda_{\max }$ of $228 \mathrm{~nm}$. This method was validated before the sample analysis for linearity (50 to $4,000 \mathrm{ng} / \mathrm{mL}$ ) using gliclazide standard drug.

\section{Pharmacokinetic analysis}

The plasma concentrations of gliclazide obtained from the HPLC analysis were used to build pharmacokinetic profiles by plotting drug concentration vs time profile curves. All the estimated pharmacokinetic parameters were reported as Mean \pm SD. Determination of pharmacokinetic parameters was done using Phoenix ${ }^{\mathbb{R}} \mathrm{WinNonlin}$ software version 6.3 (USA). The non-compartmental method was used for determination of pharmacokinetic parameters such as time to reach maximum plasma concentration $\left(\mathrm{T}_{\max }\right)$, maximum plasma concentration $\left(\mathrm{C}_{\max }\right)$, elimination rate constant $\left(\mathrm{K}_{\mathrm{el}}\right)$, area under the curve from 0 to $12\left(\mathrm{AUC}_{0-12}\right)$ and area under the curve from 0 to infinity $\left(\mathrm{AUC}_{0-\infty}\right)$. Half-life $\left(\mathrm{t}_{1 / 2}\right)$ was calculated as $0.693 / \mathrm{K}_{\mathrm{el}}$.

\section{RESULTS AND DISCUSSION}

\section{Criteria for the selection of components}

One of the factors involved for the choice of components in the microemulsion system was solubility of the drug, so that on dilution in the gut the drug should not precipitate. Therefore it is important that the drug has high solubility in all the components used in the microemulsion system.

The results from the solubility study showed that olive oil has highest solubility of $16.73 \mathrm{mg} / \mathrm{mL}$ among all the oils used (Figure 1). Tween 80 and propylene glycol had more solubility of $27.38 \mathrm{mg} / \mathrm{mL}$ and $20.31 \mathrm{mg} / \mathrm{mL}$ compared to tween 20 and PEG 400 (Figure 2). Thus olive oil, tween 80 and propylene glycol were chosen as the suitable components of microemulsion system.

\section{Drug excipient compatibility studies}

The FT-IR spectrum shows the important functional groups present in the drug. Drug excipient compatibility studies are performed to eliminate any compatibility issues of any of the components in the microemulsion system with the drug. The spectrum indicated that none of the components interfere with the functional group of the drug.

\section{Pseudoternary phase diagrams}

Construction of Pseudoternary phase diagrams taking variable concentrations of tween 80 (surfactant) with hydrophilic lypophilic balance (HLB) value of 15 , pro- 


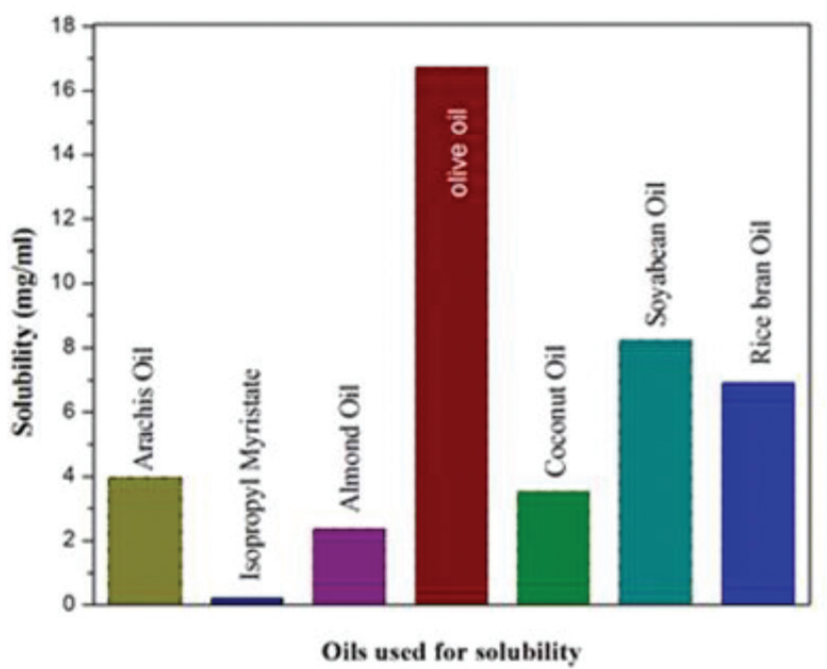

Figure 1: Solubility of gliclazide in oils.

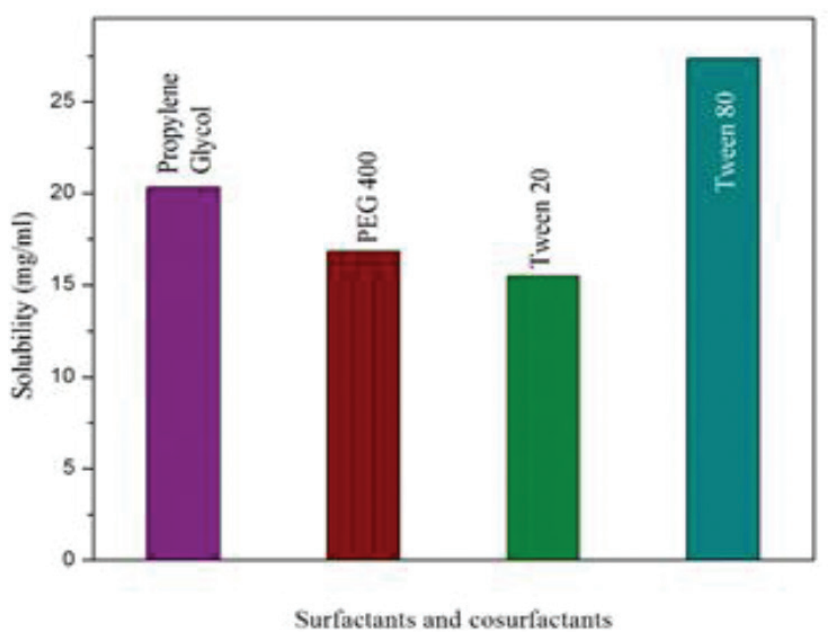

Figure 2: Solubility of gliclazide in surfactants and cosurfactants.

Phase Diagram of Gliclazide emulsion

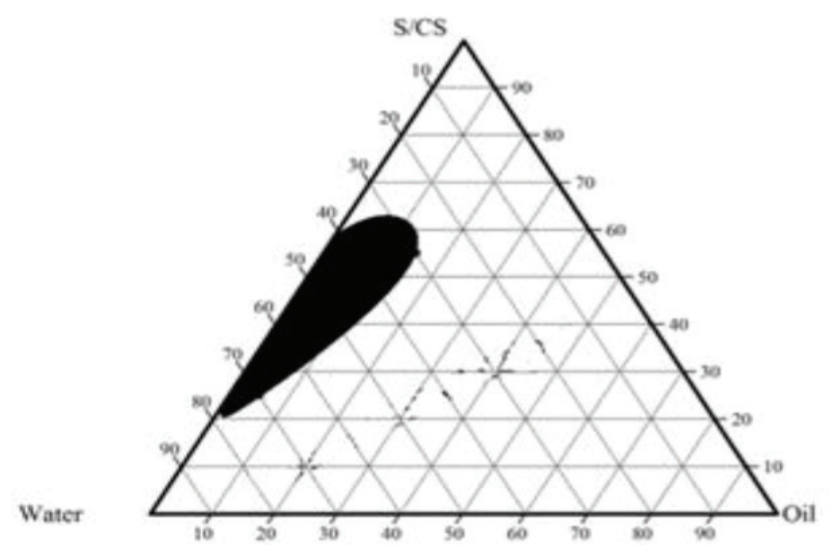

Figure 3: Pseudoternary phase diagram for gliclazide with varying ratio of oil, surfactant, cosurfactant and water. Shaded area represents oil in water microemulsion region.

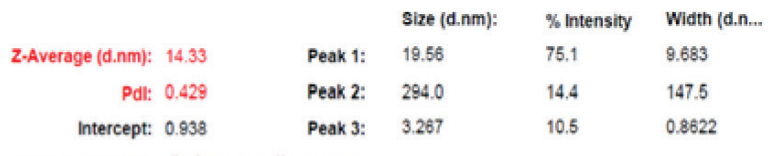

Result quality: Refer to quality report

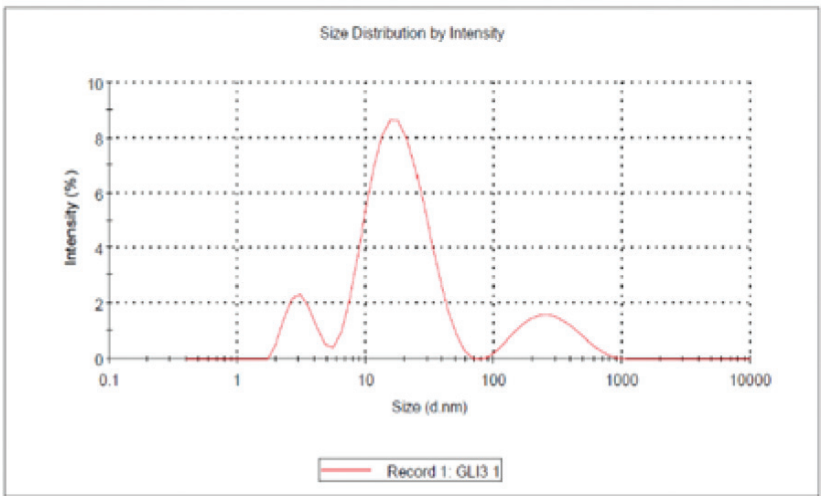

Figure 4: Droplet size measurement of G3 microemulsion by dynamic light scattering technique.

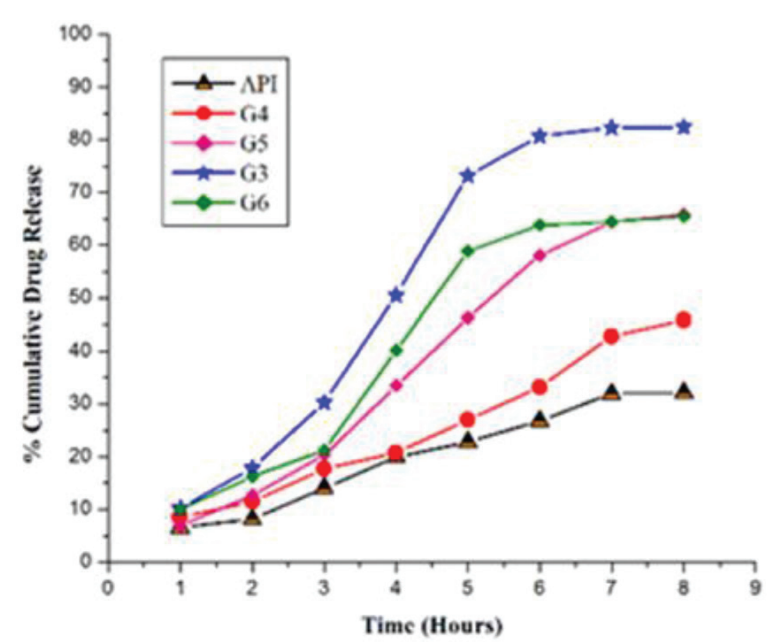

Figure 5: In-vitro release profile of gliclazide in microemulsions.

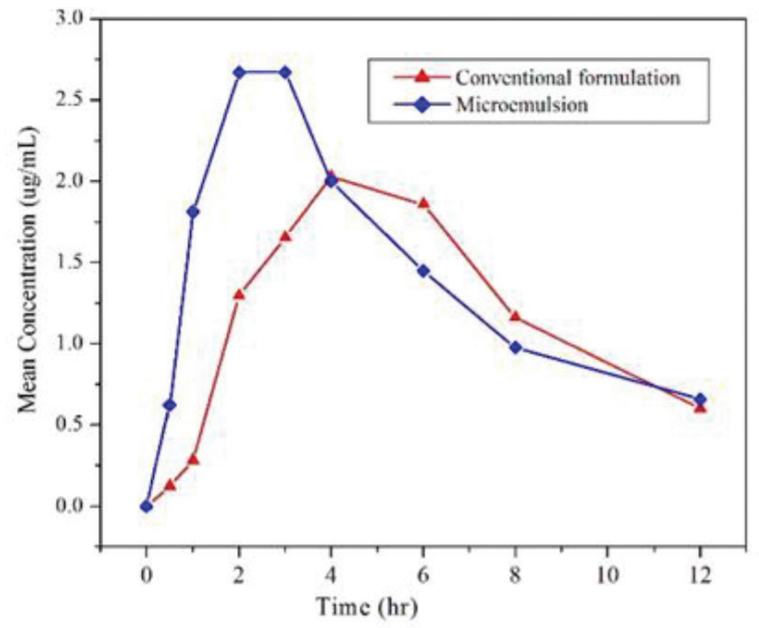

Figure 6: Increase in plasma concentration of gliclazide after oral administration of microemulsion formulation in comparison with conventional tablet formulation. 
pylene glycol (co-surfactant), olive oil as oil phase and distilled water as aqueous phase gave crucial information (Figure 3).

It is clear that when surfactant and co-surfactant $\left(\mathrm{S}_{\text {mix }}\right)$ concentration is low the emulsion formed is biphasic and unstable. Such emulsions are turbid and milky white. As the $\mathrm{S}_{\text {mix }}$ ratio increases, the clear, translucent to transparent microemulsions are formed which are stable and there is no phase separation. Another important factor is the concentration of oil in the microemulsion system which is required to solubilize the maximum quantity of drug. As the oil concentration increases, phase separation occurs. To prevent phase separation, $\mathrm{S}_{\text {mix }}$ ratio has to be increased which results in microemulsion system which may cause gastric irritation. Such formulations are highly viscous and not free flowing. Hence the pseudoternary phase diagram gives relevant information on the optimum ratio of oil, surfactant and co-surfactant that has to be used for preparation of a thermodynamically stable microemulsion system. To check the usefulness of the formulated microemulsion as suitable drug delivery system for gliclazide, the drug equivalent to one dose is incorporated into the oil phase and similar phase diagrams were constructed. The phase behavior of the drug loaded system did not change. The monophasic, clear and transparent formulations were further characterized for thermodynamic stability as one of the criterion to optimize the best formulation (Table 1). The nonionic surfactants and cosurfactants; tween 80 , propylene glycol and polyethylene glycol 400 used in the formulation reduce the interfacial tension between oily phase and aqueous phase that results in mono phasic microemulsion that remains stable over a period of time. Tween 80 is the commonly added pharmaceutical excipient that is considered non-toxic and inert, used to increase aqueous solubility.

\section{Thermodynamic stability study}

The formulations which passed the visual tests and appeared clear and transparent were exposed to stress studies such as centrifugation, heating-cooling cycle and freeze-thaw cycle. G-3 and G-6 formulations cleared the stress tests and were further evaluated.

\section{Physicochemical characterization Conductivity measurements}

The electrical conductivity was measured to understand the category of the microemulsion prepared as one among oil continuous, bicontinuous or water continuous. It was based upon percolation theory where conductivity was seen rapidly increasing with the increase in the amount of water. The swift increase of conductivity continues up to $40 \%(\mathrm{w} / \mathrm{w})$ of aqueous phase addition and then onwards conductivity remained stagnant with further titration with water. A slight decrease in conductivity was observed on further dilution with water. These observations clearly point that the microemulsion prepared is water continuous type or oil in water microemulsion. When the conductivity measurement was done with drug-loaded microemulsion, the pattern followed was similar to that of drug unloaded microemulsion.

\section{pH}

The $\mathrm{pH}$ of the selected formulations G3 and G6 was found to be $6.4 \pm 0.100$ and $6.8 \pm 0.120$, respectively. It was observed that $\mathrm{G} 6$ has higher $\mathrm{pH}$ value due to higher surfactant content.

\section{Viscosity}

The viscosity of G3 and G6 formulations was $50.0 \pm$ 0.01 and $240.5 \pm 0.08 \mathrm{cPs}$, respectively. With the increase in concentration of Tween 80 and the co-surfactant 1,2-propylene glycol, the viscosity also increased.

\section{Droplet size measurement}

The size of the droplets in G3 was found to be $14.3 \mathrm{~nm}$ with a low poly dispersity index (PDI: 0.429) (Figure 4).

\section{Zeta potential of microemulsion}

Zeta potential of G3 formulation was found to be $-0.05 \mathrm{mV}$. Aggregation is not expected to happen, due to the slightly negative charge of the droplets.

\section{In vitro release studies}

Release and diffusion of the drug from the microemulsion was calculated using the data of percentage drug diffused in the given time into the equations of zero order, first order, Higuchi and Korsmeyer Pappas model. Regression coefficients of all formulations in different orders were compared.

The in vitro drug release studies have shown the drug release for the optimized formulation across the cellulose membrane followed Korsmeyer Pappas model (Table 2). This was concluded by higher regression coefficient value in the curve fitting. Drug release from the G3 microemulsion and gliclazide suspension was found to be as $82.4 \%$ and $32.19 \%$ respectively (Figure 5). Surfactants and co-surfactants solubilize the oil by forming micelles thereby reducing the interfacial tension between oil and water. Hence the oil dissolved drugs solubility will be improved. Microemulsion showed higher drug release as compared to plain drug solution which may be due to solubility enhancing component of the surfactant and co-surfactant. 
Table 1: Formulations subjected to thermodynamic stability tests

\begin{tabular}{|c|c|c|c|}
\hline $\begin{array}{c}\text { Formulation } \\
\text { Code }\end{array}$ & $\begin{array}{c}\mathbf{S}_{\text {mix }} \\
(\% \mathbf{\%} / \mathbf{v})\end{array}$ & $\begin{array}{c}\text { Oil } \\
(\%)\end{array}$ & Appearance \\
\hline G3 & 25 & 5 & Clear and transparent \\
\hline G4 & 35 & 7.5 & Clear and transparent \\
\hline G5 & 45 & 10 & Clear and transparent \\
\hline G6 & 55 & 15 & Clear and transparent \\
\hline
\end{tabular}

\section{Table 2: Regression values for different kinetic models}

\begin{tabular}{|c|c|c|c|c|c|}
\hline \multirow{2}{*}{ Formulations } & \multirow{2}{*}{$\begin{array}{c}\text { \% Cumulative Drug } \\
\text { Release at 8 h }\end{array}$} & Zero order & First Order & Higuchi & Korsmeyer Pappas \\
\cline { 3 - 6 } & & 0.9206 & 0.9356 & 0.9401 & 0.9672 \\
\hline G3 & 82.4 & 0.9826 & 0.9644 & 0.9386 & 0.9670 \\
\hline G4 & 45.8 & 0.9743 & 0.9722 & 0.9618 & 0.9854 \\
\hline G5 & 65.8 & 0.9305 & 0.9254 & 0.9875 & 0.9458 \\
\hline G6 & 65.4 & 0.979 & 0.9824 & 0.9729 & 0.9679 \\
\hline Pure Drug (API) & 32.2 & & & & \\
\hline
\end{tabular}

Table 3: Accelerated Stability Study of G3 formulation

\begin{tabular}{|c|c|c|c|c|c|}
\hline $\begin{array}{c}\text { Temperature/Time } \\
\text { period }\end{array}$ & $\begin{array}{c}\text { OPhysical } \\
\text { appearance }\end{array}$ & Phase separation & Centrifugation Test & Droplet size $(\mathrm{nm})$ & Assay (\%) \\
\hline \multicolumn{6}{|c|}{$25^{\circ} \mathrm{C} \pm 2{ }^{\circ} \mathrm{C} / 60 \% \pm 5 \% \mathrm{RH}$} \\
\hline 0 Month & Clear, transparent & monophasic & Pass & 23 & 99.4 \\
\hline 1 Month & $\begin{array}{l}\text { No colour change/ } \\
\text { cracking/ creaming }\end{array}$ & none & Pass & 27 & 96.8 \\
\hline 2 Months & Clear, transparent & none & Pass & 32 & 97.2 \\
\hline 3 Months & $\begin{array}{l}\text { No colour change/ } \\
\text { cracking/ creaming }\end{array}$ & none & Pass & 36 & 98.2 \\
\hline 6 Months & $\begin{array}{l}\text { No colour change/ } \\
\text { cracking/ creaming }\end{array}$ & none & Pass & 37 & 96.8 \\
\hline \multicolumn{6}{|c|}{$40^{\circ} \mathrm{C} \pm 2{ }^{\circ} \mathrm{C} / 75 \% \pm 5 \% \mathrm{RH}$} \\
\hline 0 Month & Clear, transparent & monophasic & Pass & 23 & 99.4 \\
\hline 1 Month & $\begin{array}{l}\text { No colour change/ } \\
\text { cracking/ creaming }\end{array}$ & none & Pass & 42 & 98.4 \\
\hline 2 Months & Clear, transparent & none & Pass & 51 & 97.9 \\
\hline 3 Months & $\begin{array}{l}\text { No colour change/ } \\
\text { cracking/ creaming }\end{array}$ & none & Pass & 57 & 94.7 \\
\hline 6 Months & $\begin{array}{l}\text { No colour change/ } \\
\text { cracking/ creaming }\end{array}$ & none & Pass & 83 & 97.6 \\
\hline
\end{tabular}

\begin{tabular}{|c|c|c|}
\hline Parameters & Conventional formulation & Microemulsion Formulation \\
\hline $\mathrm{Cmax}(\mu \mathrm{g} / \mathrm{mL})$ & $2.118 \pm 0.169$ & $2.998 \pm 0.419$ \\
\hline $\operatorname{Tmax}(\mathrm{h})$ * & $6(4-6)$ & $2.5(2-3)$ \\
\hline AUC0-t $(\mu \mathrm{g} \cdot \mathrm{h} / \mathrm{mL})$ & $14.436 \pm 0.657$ & $17.006 \pm 0.966$ \\
\hline $\mathrm{AUCO}-\infty(\mu \mathrm{g} \cdot \mathrm{h} / \mathrm{mL})$ & $18.077 \pm 1.837$ & $22.247 \pm 2.731$ \\
\hline$T_{1} 1 / 2(h)$ & $4.01 \pm 1.188$ & $5.372 \pm 1.817$ \\
\hline K el (h-1) & $0.188 \pm 0.062$ & $0.138 \pm 0.033$ \\
\hline
\end{tabular}

*Tmax is represented by median value (range) 


\section{Accelerated stability study}

The results of the accelerated stability studies tabulated in Table 3 show that the microemulsion did not change significantly in the physical appearance, assay and droplet size. On microscopic observation, no droplet aggregation was observed and the maximum globule size observed was $83 \mathrm{~nm}(<100 \mathrm{~nm})$.

\section{Determination of drug content}

The amount of drug present in the stable microemulsion formulation $\mathrm{G} 3$ was found to be $99.4 \%$.

\section{In-vivo pharmacokinetic study}

The plasma concentration time profile of microemulsion and conventional tablet formulation in rabbit at dose equivalent to $80 \mathrm{mg}$ of gliclazide is shown in Figure 6. Microemulsion administration resulted in swift rise of plasma gliclazide level up to $\mathrm{C}_{\max } 2.998 \pm 0.419 \mu \mathrm{g} / \mathrm{mL}$ and $\mathrm{AUC}^{0-\mathrm{t}}$ value was calculated to be $17.006 \pm 0.966$ $\mu \mathrm{g} \cdot \mathrm{h} / \mathrm{mL}$ (Table 4). The observed pharmacokinetic parameters of gliclazide for the reference tablet formulation from this study, was in agreement with literature results ${ }^{15}$. Relative Bioavailability of gliclazide from microemulsion formulation was found to be greater than the bioavailability from that of marketed tablet formulation. The peak exposure of gliclazide was 1.42 fold higher and the extent of exposure was found to be 1.18 to 1.23 fold greater for microemulsion compared to the reference tablet formulation.

Microemulsions are known to have higher solubility in comparison to conventional formulations, and this strategy has been applied for improving solubility of drugs that have poor aqueous solubility ${ }^{16}$. Gliclazide is a BCS class II drug that is known for low solubility and high permeability. The effective surface area of this drug would directly influence its solubility and the dissolution rate. Thus high aqueous solubility at the site of absorption determines the rate of absorption.

The increased absorption of microemulsion can be attributed to nano sized fine droplets as observed in droplet size analysis. This increased surface area has direct impact on the improved contact with intestinal mucosa and thus better absorption. This is clearly indicated in reduced $\mathrm{T}_{\max }$ for the microemulsion. Thus gliclazide microemulsion shows superior pharmacokinetic behavior owing to the improved aqueous solubility and enhanced surface area.

\section{CONCLUSION}

The efficient formation of drug loaded microemulsion of gliclazide with droplet size in the nanometer range has facilitated the incorporation of poorly water soluble drug gliclazide into the oil in water emulsion system. Effective solubilization of gliclazide was accomplished using the microemulsification method. It is evident that this novel formulation improves in vitro diffusion and systemic exposure that evidently points towards its better therapeutic efficacy to be used as oral drug therapy.

\section{REFERENCES}

1. Kawabata Y, Wada K, Nakatani M, Yamada S, Onoue S. Formulation design for poorly water-soluble drugs based on biopharmaceutics classification system: basic approaches and practical applications. International journal of pharmaceutics. 2011 Nov 25;420(1):1-0.

2. Klang V, Matsko NB, Valenta C, Hofer F. Electron microscopy of nanoemulsions: an essential tool for characterisation and stability assessment. Micron. 2012 Feb 29;43(2):85-103.

3. Varshosaz J, Talari R, Mostafavi SA, Nokhodchi A. Dissolution enhancement of gliclazide using in situ micronization by solvent change method. Powder Technology. 2008;187(3):222-30.

4. Mandal S, Mandal SD, Surti N, Patel VB. Development of microemulsion formulation for the solubility enhancement of flunarizine. Pharm. Lett. 2010;2(3):227-36.

5. G Patel S, J Rajput S, Groshev A, B Sutariya V. Preparation and characterization of microemulsion of cilostazol for enhancement of oral bioavailability. Current drug delivery. 2014 Jun 1;11(4):531-40.

6. Buyukozturk F, Benneyan JC, Carrier RL. Impact of emulsion-based drug delivery systems on intestinal permeability and drug release kinetics. Journal of controlled release. 2010; 142(1):22-30.

7. Chaudhary A, Nagaich U, Gulati N, Sharma VK, Khosa RL, Partapur MU. Enhancement of solubilization and bioavailability of poorly soluble drugs by physical and chemical modifications: A recent review. J Adv Pharm Educ Res. 2012; 2(1):32-67.

8. Lawrence MJ, Rees GD. Microemulsion-based media as novel drug delivery systems. Advanced drug delivery reviews. 2000 Dec 6;45(1):89-121.

9. Danielsson I, Lindman B. The definition of microemulsion. Colloids and Surfaces. 1981 Dec 1;3(4):391-2.

10. McClements DJ. Nanoemulsions versus microemulsions: terminology, differences, and similarities. Soft matter. 2012;8(6):1719-29.

11. Nirmala MJ, Mukherjee A, Chandrasekaran N. Improved efficacy of fluconazole against candidiasis using bio-based microemulsion technique. Biotechnology and applied biochemistry. 2013 Jul 1;60(4):417-29.

12. Nipun TS, Islam SA. SEDDS of gliclazide: Preparation and characterization by in-vitro, ex-vivo and in-vivo techniques. Saudi Pharmaceutical Journal. 2014;22(4):343-8.

13. Huynh-Ba K, editor. Handbook of stability testing in pharmaceutical development: regulations, methodologies, and best practices. Springer Science \& Business Media; 2008.

14. Bandarkar SF, Ibrahim SK. Lyophilized Gliclazide poloxamer, solid dispersions for enhancement of in vitro dissolution and in vivo bioavailability. Int J Pharm Pharm Sci. 2011;3(S2):122-7.

15. Sarkar A, Tiwari A, Bhasin PS, Mitra M. Pharmacological and Pharmaceutical Profile of Gliclazide: A Review. Journal of Applied Pharmaceutical Science. 2011;1(09):11-9.

16. Patel V, Kukadiya H, Mashru R, Surti N, Mandal S. Development of microemulsion for solubility enhancement of clopidogrel. Iranian Journal of Pharmaceutical Research. 2010:327-34. 


\section{SUMMARY}

- The purpose of this study was to prepare liquid oral microemulsion for poorly water soluble drug, Gliclazide and increase its aqueous solubility.

- The oil in water microemulsion of gliclazide proved to be far superior than the conventional solid dosage form in terms of in vitro release and in vivo pharmacokinetic behavior.

- This novel formulation will have better patient compliance and therapeutic efficacy.

Cite this article: Kamath $\mathrm{H}$ and Sivakumar A. Microemulsion Based Formulation as Drug Delivery System for Gliclazide. Indian J of Pharmaceutical Education and Research. 2017;51(4S):S571-S59. 